\title{
An Electrophoretic Study of Enzymes as a Tool in the Taxonomy of the Dermatophytes
}

\author{
By MERIEL G. JONES† AND W. C. NOBLE* \\ Department of Bacteriology, Institute of Dermatology, Homerton Grove, \\ London E9 6BX, U.K.
}

(Received 4 August 1981; revised 24 September 1981)

\begin{abstract}
Zymogram patterns from 84 strains of dermatophyte fungi were obtained using polyacrylamide gradient gel electrophoresis of total cell protein extracts. The enzymes investigated were $\alpha$-naphthyl acetate esterase, acid phosphatase, lactate dehydrogenase, malate dehydrogenase, tetrazolium oxidase and catalase. These patterns were used to construct similarity matrices and dendrograms using computerized techniques. The results showed that zymograms allowed some species to be readily recognized despite morphological variation. This was also seen in the dendrograms where, in addition, groupings based on ecological or sexual criteria could be distinguished.
\end{abstract}

\section{INTRODUCTION}

The dermatophytes are a closely related group of deuteromycetes which cause infection of the skin and hair in man and other mammals. Current taxonomic schemes rely on morphological characteristics such as the shape of the multicelled macroconidia, used to separate the genera, and on microconidia, spiral hyphae, nodular bodies, chlamydospores and colony texture or pigmentation. Emmons (1934) described three genera from man: Trichophyton with 12 species, Microsporum with six species and Epidermophyton with one species. Additional species have been described since that date and there are now 26 accepted species of Trichophyton, 15 of Microsporum and one of Epidermophyton.

These organisms have recently been the subject of an intensive chemotaxonomic study. Our work reported to date confirms the view that this is a group of closely related fungi which chemotaxonomic studies may fail to segregate (Davison et al., 1980; Jones \& Noble, 1981). This paper continues the series and reports a study of intracellular enzymes using polyacrylamide gel electrophoresis. Previous studies on dermatophytes by this method have been limited to small numbers of strains (Sekhon, 1977; Sekhon \& Carmichael, 1976).

\section{METHODS}

Identity of isolates. The origins and classification, according to current concepts, of the 84 strains used in this study are shown in Table 1. Isolates were grown in Sabouraud's liquid medium (Oxoid) at $30^{\circ} \mathrm{C}$ for $10 \mathrm{~d}$ using an orbital incubator (Gallenkamp) operating at $100 \mathrm{rev} \cdot \mathrm{min}^{-1}$.

Preparation of protein extracts. Mycelium $(3 \mathrm{~g})$ was placed in a clean universal bottle with $10 \mathrm{~g}$ glass beads ( $2 \mathrm{~mm}$ diam.) and $5 \mathrm{ml}$ distilled water, and disrupted by vigorous shaking using a Baird \& Tatlock flask shaker. At least five cycles of shaking $(1 \mathrm{~min})$ and cooling in crushed ice $(5-15 \mathrm{~min})$ were used to reduce the mycelium to a slurry in which no intact mycelium was visible; extra distilled water was added as necessary to maintain a uniform slurry. The final slurry was centrifuged at $36000 \mathrm{~g}$ for $30 \mathrm{~min}$ (MSE HS-18 centrifuge) and the supernatant was retained. After a second disruption of the pellet and centrifugation, the pooled supernatants were centrifuged at

† Present address: Department of Chemistry, University of Essex, Colchester CO4 3SQ, U.K. 
Table 1. Strains used in the study - classified according to Rebell \& Taplin (1978)

\begin{tabular}{|c|c|c|}
\hline Species & Source* & Code numbers \\
\hline Epidermophyton floccosum & $\begin{array}{l}\text { NCPF } \\
\text { MRL } \\
\text { SJH }\end{array}$ & $\begin{array}{l}226 \text { (pleomorphic) } \\
\text { 1613, } 2108 \\
\text { ER2129, ER6375, ES2732, ES3009, ES3026, ES3115, R921, } \\
\text { S1561 }\end{array}$ \\
\hline Microsporum canis & $\begin{array}{l}\text { NCPF } \\
\text { MRL } \\
\text { SJH } \\
\text { CMH }\end{array}$ & $\begin{array}{l}179,264,266,269 \\
1450 \\
\text { ES2504, S1220 } \\
73571,77457 \text { (dysgonic strains) }\end{array}$ \\
\hline \multirow[t]{2}{*}{ M. gypseum } & NCPF & $\begin{array}{l}\text { 412, } 413 \text { [compatible with } N . \text { gypsea (Stockdale, 1963) IMI } \\
86175,86176 \text { ] } \\
414,415 \text { [compatible with } N \text {. incurvata (Stockdale, 1963) IMI } \\
86518,104076 \text { ] }\end{array}$ \\
\hline & SJH & $\begin{array}{l}\text { EF339, EP1431, EP3236, EP4783, EP5759, EQ5948, EN6244, } \\
\text { P2341, lynas }\end{array}$ \\
\hline M. persicolor & SJH & $\mathrm{MP}, \mathrm{EQ} 7970$ \\
\hline M. fulvum & $\mathrm{NCPF}$ & $\begin{array}{l}\text { 390, 391 [compatible with } N . \text { fulva (Stockdale, 1963) IMI } \\
86179,86180 \text { ] }\end{array}$ \\
\hline M. audouinii & $\begin{array}{l}\text { NCPF } \\
\text { SJH }\end{array}$ & $\begin{array}{l}188 \\
\text { ET3600, S3413 }\end{array}$ \\
\hline M.ferrugineum & SJH & Evans, 193, EQ3816 \\
\hline M. langeroni & SJH & ED39, EJ2669 \\
\hline$M$. rivalieri & SJH & 12468, EG2361 \\
\hline \multirow[t]{3}{*}{ Trichophyton mentagrophytes } & NCPF & $232,235,237$ (granular); 336 (fluffy) \\
\hline & MRL & $\begin{array}{l}9403 \text { (granular); 1619, 8872, } 9488 \text { (fluffy); B1207, 1325, 1615, } \\
4072,4311 \text { (S. Africa, fluffy) }\end{array}$ \\
\hline & SJH & EN8153 (granular) \\
\hline \multirow[t]{3}{*}{ T. rubrum } & NCPF & $113,325,419,421$ \\
\hline & MRL & $\mathrm{C} 1016,3397,5034,5387,6178,6371,6805$ \\
\hline & SJH & Q3357 \\
\hline \multirow[t]{2}{*}{ T. tonsurans } & NCPF & 145 \\
\hline & SJH & EQ8426, ER385, R288 \\
\hline T. erinacei & NCPF & 375 \\
\hline T. gallinae & NCPF & 438 \\
\hline T. verrucosum & $\mathrm{NCPF}$ & 510 \\
\hline T. fischeri & NCPF & 519 \\
\hline \multirow[t]{2}{*}{ T. violaceum } & SJH & $\mathrm{Tv}$ \\
\hline & $\mathrm{CMH}$ & 89570,89571 (scalp of siblings) \\
\hline
\end{tabular}

* CMH, Central Middlesex Hospital, London, strains provided by Mr Duncan Tucker; MRL, Mycological Reference Laboratory, PHLS, London School of Hygiene and Tropical Medicine, London; NCPF, National Collection of Pathogenic Fungi (at the Mycological Reference Laboratory, London); SJH, St John's Hospital for Diseases of the Skin, London.

$3000 \mathrm{~g}$ for $1 \mathrm{~h}$. The protein concentration of this extract was $7-15 \mathrm{mg} \mathrm{ml}^{-1}$. The extract was freeze-dried, resuspended in the minimum amount of electrophoresis buffer and again centrifuged to remove any remaining particulate matter. The final extract contained $40-70 \mathrm{mg}$ protein $\mathrm{ml}^{-1}$ and was stored in small glass vials at $-20^{\circ} \mathrm{C}$ until required.

Preparation of electrophoresis gels. Polyacrylamide gradient gels were made as described below. Stock solutions were prepared as follows: (1) $30 \%(\mathrm{w} / \mathrm{v}$ ) acrylamide in electrophoresis buffer (acrylamide : bisacrylamide ratio $1: 19)$ at $4{ }^{\circ} \mathrm{C} ;(2) 10 \%(\mathrm{w} / \mathrm{v})$ ammonium persulphate as initiator; (3) $10 \%(\mathrm{v} / \mathrm{v})$ dimethylaminopropiononitrile in water as catalyst; (4) eiectrophoresis buffer - $0.09 \mathrm{M}$-Tris base, $0.08 \mathrm{M}$-boric acid, $0.0025 \mathrm{M}$-EDTA, pH 8.35 at room temperature; (5) $5 \%(\mathrm{v} / \mathrm{v})$ ethanol as overlay at room temperature; (6) $40 \%(\mathrm{w} / \mathrm{v})$ sucrose as underlay at $4^{\circ} \mathrm{C}$. Gels were prepared in batches of 16 using a gradient forming tower (Uniscil Ltd, UK) such that reproducible gradients of 5-25\% were formed. Overlays and underlays were necessary to obtain controlled polymerization and smooth surfaces at the top and bottom of the gels.

A Pharmacia type GE4 electrophoresis tank and type EPS 500/400 power supply was used. After the gels had been inserted, a plastic sample applicator was placed on the gel and $10 \mu \mathrm{l}$ samples were applied. A standard time of $2000 \mathrm{~V}-\mathrm{h}$ was used for all gels.

Staining of gels. All chemicals were obtained from Sigma. Gels were stained immediately after electrophoresis by removing each gel from its cassette and immersing it in $50 \mathrm{ml}$ of fresh stain in a transparent plastic box. Gels 
were then incubated in the dark at $37^{\circ} \mathrm{C}$ until bands of activity appeared (see individual staining methods). When staining appeared complete, the stain was discarded, and the gel was washed under running water and then stored in $7 \%(\mathrm{w} / \mathrm{v})$ acetic acid in a sealed box at $4{ }^{\circ} \mathrm{C}$ or at room temperature.

The enzymes investigated and corresponding staining methods were as follows: esterases (Goullet, 1977) - the substrates were $\alpha$-naphthyl acetate, $\beta$-naphthyl acetate, $\beta$-naphthyl butyrate, $\beta$-naphthyl laurate and $\beta$-naphthyl oleate; phosphatases (El-Sharkawy \& Huisingh, 1971) - the substrate was $\alpha$-naphthyl phosphate assayed at pH 4.6 and 8.8; lactate dehydrogenase (Chua et al., 1978); malate dehydrogenase (Shaw \& Prasad, 1970); tetrazolium oxidase (Shaw \& Prasad, 1970); catalase - gradient gels were made incorporating $1 \%(\mathrm{w} / \mathrm{v})$ starch and stained according to Shaw \& Prasad (1970).

Recording and analysis of enzyme patterns. The gels, or their photographs, were compared to determine the number and position of isoenzymes of each enzyme. Since the absolute mobility varied slightly from gel to gel, the position of isoenzymes relative to each other was considered more important in determining if bands were identical. A reference sample of $M$. canis 266, was included on many gels to aid in this comparison. Each strain was then scored 0 or 1 for the absence or presence of each isoenzyme. Strains were given arbitrary numbers from 1 to 84 and the scores for each were stored in a Commodore PET microcomputer system as files labelled 1-84. A similarity matrix and dendrograms were then formed using programs adapted from those of Jackman (1982).

Two measures of similarity were used, both described in detail by Sneath \& Sokal (1973). These were the simple matching coefficient $\left(S_{S M}\right)$ and the Jaccard coefficient $\left(S_{J}\right)$. In the former, both positive and negative matches are used as a measure, while the latter only considers positive matches. Finally, each similarity matrix was clustered using the unweighted pair group method with averages (UPGMA) (Sneath \& Sokal, 1973).

\section{RE SULTS}

Figure 1 shows the results, in diagrammatic form, for the $\alpha$-naphthyl acetate esterase of $M$. canis 266 run on a number of occasions. As expected, the greatest variability was encountered when the sample was run on separate gels on separate occasions, but overall reproducibility was good. Figure 2 shows partial data for selected strains in diagrammatic form. Overall similarities and differences can be appreciated from this figure.

\section{Individual enzymes}

Esterases. In preliminary studies the specificity of the esterases was investigated. Of the three substrates which revealed enzyme activity, namely $\beta$-naphthyl butyrate, $\alpha$-naphthyl acetate and $\beta$-naphthyl acetate, only one, $\alpha$-naphthyl acetate, was selected for the survey of all
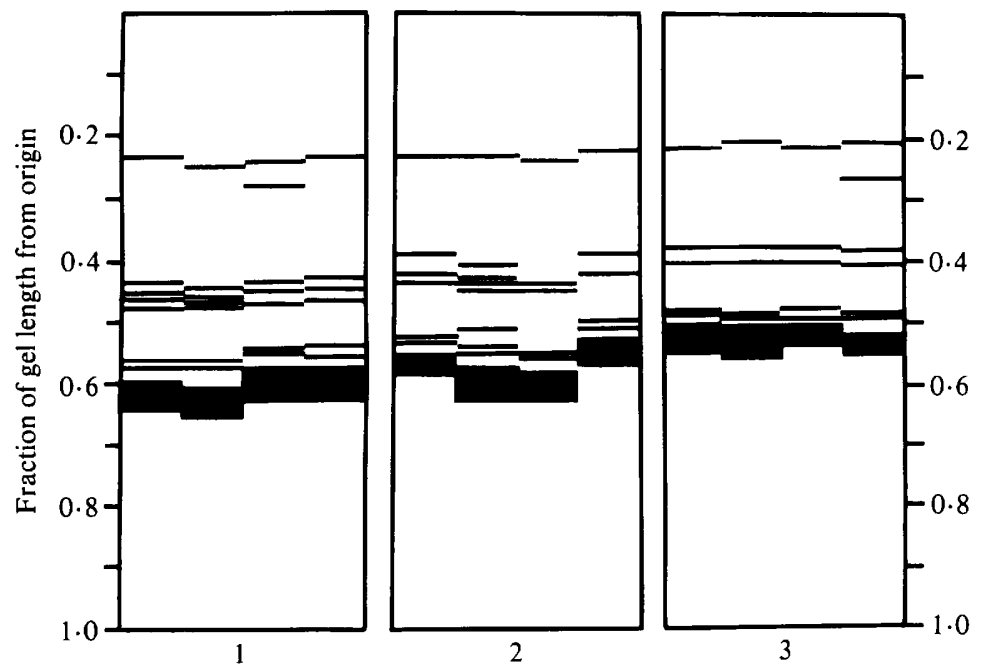

Fig. 1. Electrophoresis of $\alpha$-naphthyl acetate esterase from $M$. canis 266 on a number of occasions. (1) Sample A run on four separate gels from the same batch on the same occasion. (2) Sample B run on four separate gels from the same batch on four separate occasions. (3) Sample B run on a single gel. 


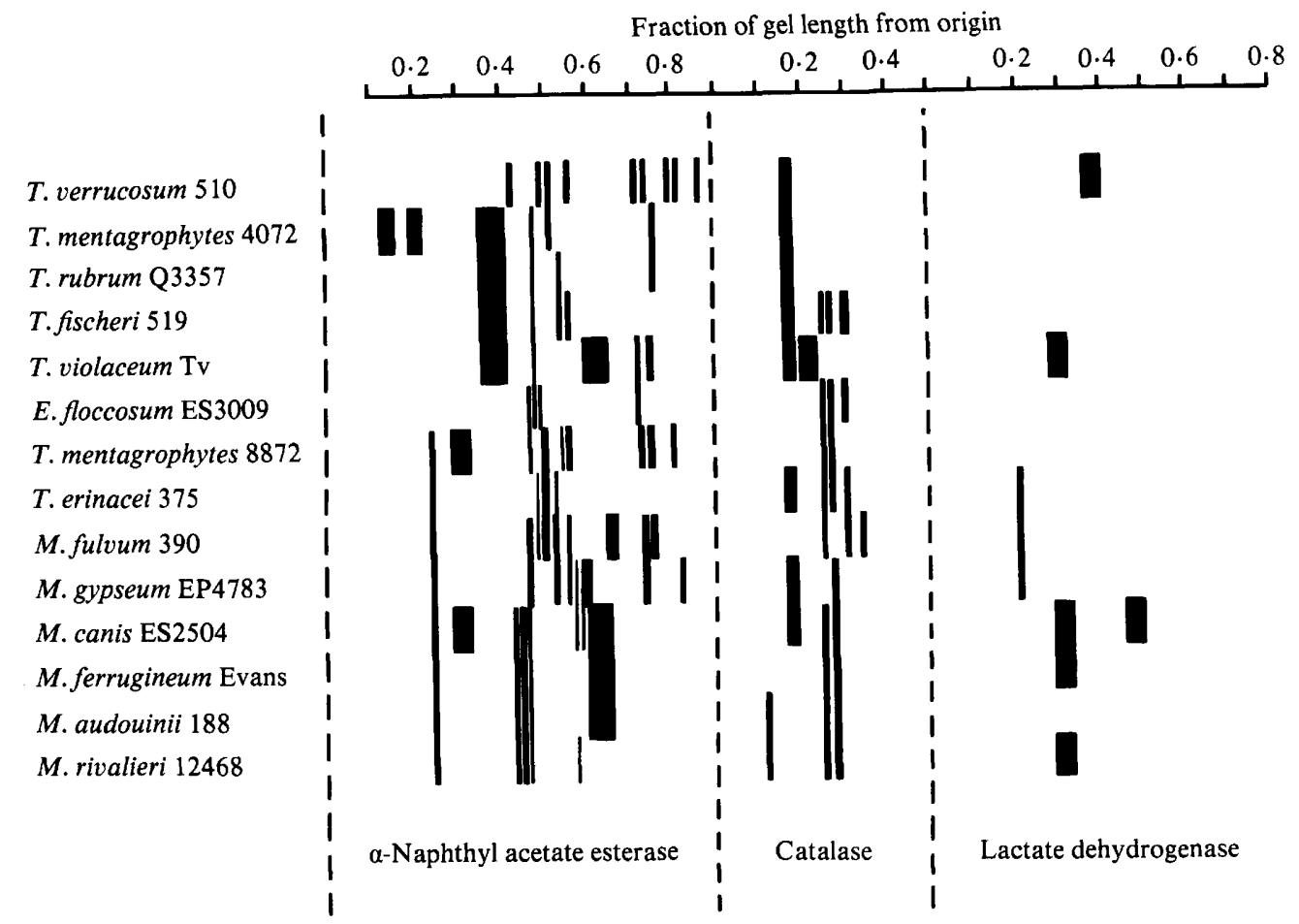

Fig. 2. Partial data for selected strains shown in diagrammatic form.

the strains. This produced more numerous and better defined bands than the other two substrates. Twenty-four different $\alpha$-naphthyl acetate esterase bands were identified. Species where a sexual (perfect) state is unknown, such as $E$. floccosum and $T$. rubrum, showed a great homogeneity of enzyme patterns. In $M$. gypseum and $T$. mentagrophytes, where sexual reproduction is well described, the patterns were more diverse. Patterns from $M$. ferrugineum, $M$. audouinii, $M$. langeroni and $M$. rivalieri (the latter two often considered as variants of $M$. audouinii) were very similar to each other and to $M$. canis.

Phosphatases. Initial studies showed that activity at both $\mathrm{pH}$ values was coincident, but staining was more intense at the lower $\mathrm{pH}(4 \cdot 6)$. Therefore, only acid phosphatase was included in this survey. Eight bands were detected and these were common to several species.

Lactate dehydrogenase. All $M$. canis and most other Microsporum species showed lactate dehydrogenase activity, but activity could not be detected in $E$. floccosum or in many Trichophyton isolates.

Malate dehydrogenase. This was not detected in most T. rubrum strains, in T. fischeri, or in several Microsporum strains. However, E. floccosum and $M$. canis produced distinctive patterns.

Tetrazolium oxidase. This enzyme was readily detected in all strains and some of the eight bands were common to several species. Some variation was evident among T. mentagrophytes strains, similar to that for $\alpha$-naphthyl acetate esterase. There was again a great similarity between $M$. canis, $M$. ferrugineum, $M$. audouinii, $M$. langeroni and $M$. rivalieri. Trichophyton rubrum was distinct from other Trichophyton but identical to E. floccosum. In common with other enzymes, the tetrazolium oxidase activity of the single $T$. verrucosum strain appeared unique.

Catalase. Many common catalase bands were detected and no distinctive patterns emerged. 
Percentage similarity

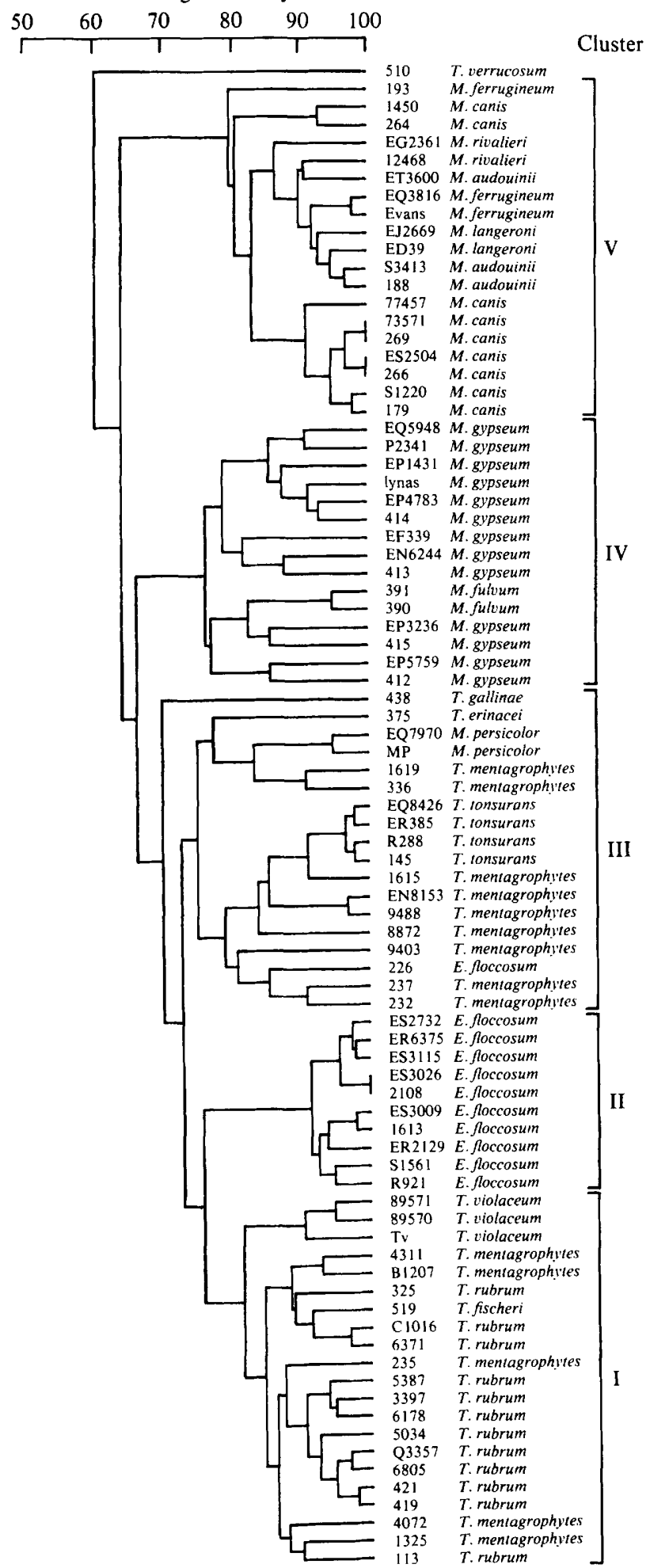

Fig. 3. Dendrogram for $S_{S M}$ showing five major clusters. Strain numbers are shown with the nomenclature according to Rebell \& Taplin (1978) 


\section{Clustering of strains}

In the $S_{S M}$ /UPGMA analysis, all strains clustered at $60 \%$ similarity (Fig. 3 ). There were five major clusters plus $T$. verrucosum which formed a taxon of its own. Cluster I contained all $12 T$. rubrum strains, the three $T$. violaceum and the single $T$. fischeri strains, together with five of the $T$. mentagrophytes strains interspersed through the group. Cluster II contained 10 of the $11 \mathrm{E}$. floccosum strains. Cluster III contained the remaining nine $T$. mentagrophytes strains, together with the four $T$. tonsurans strains and the single isolates of $T$. erinace $i$ and $T$. gallinae. Also included were the two $M$. persicolor and the remaining $E$. floccosum strain. Cluster IV contained all $13 \mathrm{M}$. gypseum and the two M. fulvum strains. Cluster V contained all nine $M$. canis strains, three $M$. audouinit, three $M$. ferrugineum, two $M$. langeroni and two $M$. rivalieri strains.

The dendogram obtained from the $S_{J} /$ UPGMA analysis was very similar to that from $S_{S M}$ analysis; all strains clustered at $10.5 \%$ similarity. The main effect of using the $S_{J}$ coefficient was to divide cluster III in two by inserting cluster IV and to insert $T$. verrucosum into cluster III adjacent to $T$. gallinae.

\section{DISCUSSION}

Clusters I to V (Fig. 3) reflect both taxonomic and ecological groupings which have been noted previously (Philpot, 1978a,b). Thus, the monospecific genus E. floccosum (apart from one strain) is clearly distinguished from all other species despite its ecological similarities with, for example, $T$. rubrum. The only geophilic species included in this study, M. gypseum, was differentiated from species of other habitats but also from other Microsporum strains. In contrast, most of the tropical, anthropophilic strains ( $T$. violaceum and some $T$. mentagrophytes) fell within the same cluster as T. rubrum. Trichophyton fischeri, described as an airborne contaminant but with many affinities to T. rubrum (Kane, 1977), also lay within this cluster. Cluster V contained Microsporum strains which share a common habitat, human-prepubertal and animal hair, and some strains (namely $M$. langeroni and $M$. rivalieri) which are often only accorded varietal status (Rebell \& Taplin, 1978). This study suggests that the latter are undeserving of species status, and are indistinguishable from $M$. ferrugineum on the basis of isoenzymes.

Cluster III illustrates the problem which may be encountered when only a few isolates of each species are examined. Strains of $T$. gallinae, $T$. mentagrophytes, $T$. erinacei, $T$. tonsurans, $M$. persicolor and $E$. floccosum were recovered in this cluster, which thus contains a mixture of genera and of strains from different habitats. The taxonomic status of many of these 'species' is still not established and a study of further strains will probably reveal which of these can be regarded as distinct taxa. For example, the one strain of $T$. gallinae studied is only as similar to the members of cluster III as it is to clusters I and II; Gordon \& Little (1968) suggested that this zoophilic species may belong to the genus Microsporum rather than Trichophyton. Similarly, the status of $M$. persicolor as belonging to the genus Microsporum rather than Trichophyton was only clarified after the discovery of its perfect state (Stockdale, 1967); however, on the basis of its isoenzymes it clusters with the Trichophyton species. The status of $T$. erinace $i$ has still not been resolved and some authors would accord it only varietal status as T. mentagrophytes var. erinacei (Takashio, 1975; Padhye \& Ajello, 1977). Its status has not been clarified in the present investigations as only one representative was examined.

Further areas where this approach could be of value can be identified. A pleomorphic strain such as ER6375 is correctly grouped as E. floccosum although it is devoid of typical morphology. Two dysgonic strains of $M$. canis (73571 and 77457) are indistinguishable from typical $M$. canis strains. These methods might therefore shed some light on the elusive relation between dermatophyte morphology and species.

Examination of cluster IV shows that the morphologically similar mating types of the $M$. gypseum complex can be separated. Strains EQ5948, P2341 and lynas match strain 414 in 
mating type (Nannizzia incurvata) and strain EF339 matches strain 412 (N. gypsea) (M. J. Moore, personal communication). No mating reaction could be obtained from the remaining strains. A study of isoenzyme patterns may therefore enable mating type to be predicted and could prove invaluable for strains which cannot be induced to produce cleistothecia.

Dr Yvonne Clayton, Professor D. W. R. Mackenzie and Mr D. L. Tucker are thanked for gifts of strains and for helpful discussion. We are grateful to the Wellcome Trust for providing financial support.

\section{REFERENCES}

Chua, K. E., Crossman, E. J. \& Gilmour, C. A. (1978). Lactate dehydrogenase (LDH) isozymes in muscle of freshwater fish by iso-electric focusing in thin-layer polyacrylamide gel. Science Tools 25 , 9-11.

Davison, F. D., Mackenzie, D. W. R. \& Owen, R. J. (1980). Deoxyribonucleic acid base compositions of dermatophytes. Journal of General Microbiology $118,465-470$.

El Sharkawy, T. A. \& Huisingh, D. (1971). Differentiation among Xanthomonas species by polyacrylamide gel electrophoresis of soluble proteins. Journal of General Microbiology 68, 155-165.

Emmons, C. W. (1934). Dermatophytes. Natural groupings based on the form of the spores and accessory organs. Archives of Dermatology and Syphilology 30, 337-362.

Gordon, M. A. \& LitTle, G. N. (1968). Trichophyton (Microsporum?) gallinae ringworm in a monkey. Sabouraudia 6, 207-212.

Goullet, P. (1977). Relationships between electrophoresis patterns of esterases from Salmonella. Journal of General Microbiology 98, 535-543.

JACKMAN, P. J. H. (1982). Taxonomy of aerobic axillary coryneforms based on electrophoretic protein patterns. Ph.D. thesis, University of London, U.K.

Jones, M. G. \& Noble, W. C. (1981). A study of fatty acids as a taxonomic tool for dermatophyte fungi. Journal of Applied Bacteriology 50, 577-583.

KANE, J. (1977). Trichophyton fischeri sp. nov., a saprophyte resembling Trichophyton rubrum. Sabouraudia 15, 231-240.

Padhye, A. A. \& Ajello, L. (1977). The taxonomic status of the hedgehog fungus Trichophyton erinacei. Sabouraudia 15, 103-114.
Philpot, C. M. (1978a). Serological differences among the dermatophytes. Sabouraudia 16, 247256.

Philpot, C. M. (1978 b). Geographical distribution of the dermatophytes. A review. Journal of Hygiene $\mathbf{8 0}$, 301-313.

Rebell, G. \& TAPLIN, D. (1978). Dermatophytes: Their Recognition and Identification. Coral Gables: University of Miami Press.

SeKhon, A. S. (1977). Effects of age on fresh weight, proteins, peroxidases and other enzymes of the $(+)$, $(-)$ and crossed gymnothecial cultures of Nannizzia gypsea. Mycopathologia 60, 145-149.

SekHon, A. S. \& Carmichael, J. W. (1976). Electrophoretic analyses of proteins, peroxidases and phosphatases of single and mated cultures of Arthroderma benhamiae. Mycopathologia 58, 97100.

Shaw, C. R. \& Prasad, R. (1970). Starch gel electrophoresis of enzymes - compilation of recipes. Biochemical Genetics 4, 297-320.

SNeath, P. H. A. \& Sokal, R. R. (1973). Numerical Taxonomy. San Francisco: W. H. Freeman \& Co.

Stockdale, P. M. (1963). The Microsporum gypseum complex (Nannizzia incurvata (Stockd.), N. gypsea (Nann.) comb.nov., M. fulva sp. nova). Sabouraudia 3, 114-126.

Stockdale, P. M. (1967). Nannizzia persicolor sp.nov., the perfect state of Trichophyton persicolor Sabouraud. Sabouraudia 5, 355-359.

TAKASHIO, M. (1975). Single ascospore strain from the mating between Trichophyton mentagrophytes var. erinace and Arthroderma benhamiae. Transactions of the British Mycological Society 65, 67-76. 